\title{
PENGARUH MOTIVASI, PEMBELAJARAN, PERSEPSI DAN SIKAP TERHADAP KEPUTUSAN MAHASISWA MEMILIH JURUSAN
}

\author{
Lu'lu UI Maknunah; Fandi Sudiasmo \\ Fakultas Ilmu Sosial dan Ilmu Politik, Universitas Islam Balitar \\ Email: uul.unisba@gmail.com; fandisudiasmo@gmail.com
}

\begin{abstract}
This research was conducted at the Faculty of Social and Political Sciences, Balitar Islamic University with the aim of finding out whether attitudes, motivations, learning and perceptions influence the decisions of students choosing majors. The test used in this study is the classical assumption test including normality test, multicollinearity test and heteroscedasticity test. After the classic assumption test, a hypothesis test is performed which includes a partial test and a simultaneous test. As a result, the four independent variables namely attitude, motivation, learning and perception affect students in determining majors either partially or simultaneously. This is proven by the value of sig. in partial tests and simultaneous tests that show values less than 0.05. Therefore, it is expected that in the future, the Faculty of Social and Political Sciences will pay more attention to several psychological factors including attitudes, motivation, learning and perceptions that are proven to influence students in choosing majors, so that more and more students choose majors in the Faculty of Social Sciences and Political Science, Balitar Islamic University. In addition, it is hoped that the results of this study can be used as reference material for future research and be of benefit to the wider community, especially when choosing a major to look at various decision variables.
\end{abstract}

Keywords: Psychological Factors; Student Decisions Choosing Majors

Abstrak: Penelitian ini dilakukan di Fakultas Ilmu Sosial dan Ilmu Politik, Universitas Islam Balitar dengan tujuan untuk mencari tahu apakah sikap, motivasi, pembelajaran dan persepsi mempengaruhi keputusan mahasiswa memilih jurusan. Uji yang digunakan pada penelitian ini adalah uji asumsi klasik meliputi uji normalitas, uji multikolinieritas dan uji heteroskedastisitas.Setelah uji asumsi klasik, dilakukan uji hipotesis yang meliputi uji parsial dan uji simultan.Hasilnya, keempat variabel bebas yaitu sikap, motivasi, pembelajaran dan persepsi mempengaruhi mahasiswa dalam menentukan jurusan baik secara parsial maupun secara simultan. Hal ini terbukti dengan nilai sig. pada uji parsial dan uji simultan yang menunjukkan nilai kurang dari 0,05. Oleh karena itu, diharapkan di masa mendatang, Fakultas Ilmu Sosial dan Ilmu Politik lebih memperhatikan lagi beberapa faktor psikologis diantaranya sikap, motivasi, pembelajaran dan persepsi yang terbukti mempengaruhi mahasiswa dalam memilih jurusan, agar semakin banyak lagi mahasiswa yang memilih jurusan di Fakultas Ilmu Sosial dan Ilmu Politik, Universitas Islam Balitar. Selain itu, diharapkan hasil penelitian ini dapat dimanfaatkan sebagai bahan rujukan penelitian di masa mendatang dan bermanfaat bagi masyarakat luas terutama ketika akan memilih sebuah jurusan dapat melihat dari berbagai variabel keputusan.

Kata Kunci: Faktor Psikologis; Keputusan Mahasiswa Memilih Jurusan

\section{PENDAHULUAN}

Lembaga pendidikan merupakan suatu bidang usaha yang bergerak di bidang pelayanan jasa yaitu pendidikan yang berorientasi pada pengembangan mutu sumber daya manusia. Melalui pendidikan seseorang akan mendapatkan binaan dan bimbingan untuk mengembangkan potensi yang dimilikinya, sehingga dapat dijadikan modal untuk mengikuti persaingan dalam dunia kerja yang semakin kompetetif. Dan jenjang pendidikan yang fokus pada satu konsentrasi untuk memasuki dunia kerja yaitu pendidikan tinggi. 


\section{REFORMASI}

ISSN 2088-7469 (Paper) ISSN 2407-6864 (Online)

Volume 10 Nomor 1 (2020)

Pendidikan tinggi merupakan jenjang pendidikan tingkat akhir yang diselenggarakan untuk mempersiapkan peserta didik menjadi anggota masyarakat yang memiliki kemampuan akademik dan profesional. Berdasarkan Undang-undang Sistem Pendidikan Nasional (Sisdiknas) No. 20 Pasal 19 Tahun 2003, dalam Alma dan Hurriyati (2008), pendidikan tinggi mencangkup pendidikan diploma, sarjana, magister, spesialis dan doktor yang diselenggarakan oleh perguruan tinggi.Dalam penyelenggaraanya perguruan tinggi dapat berbentuk akademi, politeknik, sekolah tinggi, institut dan universitas.

Salah satu perguruan tinggi yang ada di Indonesia adalah Universitas Islam Balitar.Universitas Islam Balitar merupakan Perguruan Tinggi Swasta yang terletak di Blitar, Jawa Timur. Saat ini Universitas Islam Balitar memiliki 8 Fakultas yaitu, Fakultas Teknik, Fakultas Pertanian, Fakultas Peternakan, Fakultas Teknologi Informasi, Fakultas Ilmu Sosial dan Ilmu Politik, Fakultas Ekonomi, Fakultas Hukum, dan Fakultas Keguruan dan Ilmu Pendidikan.

Fakultas Ilmu Sosial dan Ilmu Politik merupakan salah satu fakultas yang ada di Universitas Islam Balitar yang banyak diminati oleh calon mahaiswa untuk memilih program studi atau jurusan sebagai tempat kuliah. Adapun jurusan yang terdapat dalam Fakultas Ilmu Sosial dan Ilmu Politik yaitu, Ilmu Administrasi Bisnis, Ilmu Administrasi Pubik, Ilmu Komunikasi, dan Sosiologi. Sejauh ini jumlah mahasiswa Fakultas Ilmu Sosial dan Ilmu Politik dari tahun ke tahun jumlahnya semakin meningkat.Hal ini dapat dilihat dari Tabel 1.

Tabel 1. Peningkatan Jumlah Mahasiswa Di Fakultas

Ilmu Sosial danIlmu Politik UNISBA Tahun 2012/2013-2016/2017

\begin{tabular}{|c|c|c|c|c|}
\hline \multicolumn{5}{|c|}{ Tahun Ajaran } \\
\hline Jurusan & $\mathbf{2 0 1 3 / 2 0 1 4}$ & $\mathbf{2 0 1 4 / 2 0 1 5}$ & $\mathbf{2 0 1 5 / 2 0 1 6}$ & $\mathbf{2 0 1 6 / 2 0 1 7}$ \\
\hline Adm. Bisnis & 28 & 30 & 152 & 154 \\
\hline Adm. Negara & 17 & 18 & 160 & 161 \\
\hline Ilmu Komunikasi & 16 & 17 & 75 & 54 \\
\hline Sosiologi & 1 & 5 & 5 & 2 \\
\hline Jumlah & $\mathbf{5 0}$ & $\mathbf{7 0}$ & $\mathbf{1 4 8}$ & $\mathbf{1 7 8}$ \\
\hline
\end{tabular}

Sumber: Bagian Akademik Fakultas Ilmu Sosial dan Ilmu Politik UNISBA (2017)

Dari data Tabel 1 dapat dilihat bahwa dari tahun ke tahun jumlah mahasiswa yang memilih jurusan di Fakultas Ilmu Sosial dan Ilmu Politik semakin mengalami peningkatan.Masing-masing jurusan mengalami fluktuasi naik turun dan penyebaran mahasiswa pada setiap jurusan masih belum merata.Hal tersebut terjadi karena setiap mahasiswa dipengaruhi oleh faktor-faktor yang mendorongnya dalam memutuskan pemilihan jurusan, dan setiap orang memiliki pertimbangan yang berbeda-beda dan faktor dominan yang mempengaruhi pengambilan keputusan tersebut.Oleh karena itu, hal tersebut harus menjadi perhatian bagi pihak fakultas untuk meningkatkan kualitas pada setiap jurusan agar dapat mempengaruhi keputusan mahasiswa dalam memilih jurusan tersebut dan dapat meningkatkan minat calon mahasiswa pada setiap jurusan.

Pengambilan keputusan mahasiswa dalam memilih jurusan yang diinginkan merupakan suatu keputusan dimana mahasiswa melakukan pertimbangan-pertimbangan yang disesuaikan dengan keadaan atau kondisi yang ada. Apabila keadaan atau kondisi yang terlihat tidak sesuai dengan apa yang diharapkan, maka akan terjadi keraguan yang dapat berakibat pada keputusan untuk tidak memilih. Dampak penetapan pilihan tesebut dapat membawa pengaruh jangka pendek dan panjang, terlebih bahwa penetapan pilihan tersebut adalah pemilihan jurusan yang dapat berdampak pada masa depan mahasiswa. 


\section{REFORMASI}

ISSN 2088-7469 (Paper) ISSN 2407-6864 (Online)

Volume 10 Nomor 1 (2020)

Dalam mengambil keputusan memilih jurusan mahasiswa sangat dipengaruhi oleh beberapa faktor.Faktor-faktor yang menjadi pertimbangan bagi mahasiswa dalam memilih jurusan diantaranya, faktor budaya, faktor sosial, faktor pribadi serta faktor psikologis.Pada penelitian ini nantinya tidak semua faktor diteliti, penelitian ini hanya mengacu pada faktor psikologis.Faktor psikologis mahasiswa terdiri dari motivasi, persepsi, pembelajaran dan sikap.

Pada penelitian sebelumnya yang dilakukan oleh Harahap (2015) dengan judul "Analisis Faktor-Faktor Yang Mempengaruhi Keputusan Mahasiswa Dalam Memilih Jurusan Akutansi Sebagai Tempat Kuliah di Universitas di Kota Pekanbaru", memiliki hasil yaitu dalam uji parsial atau uji t menunjukkan bahwa dari keempat variabel yang terdiri dari budaya, sosial, pribadi dan psikologis ada 2 variabel yang berpengaruh signifikan yaitu pribadi dan psikologis, sedangkan variabel budaya dan sosial tidak berpengaruh signifikan terhadap keputusan mahasiswa. Selain itu dalam analisis regresi berganda variabel psikologis menunjukkan pengaruh yang paling besar dari variabel lainya.Hal ini dapat disimpulkan bahwa variabel psikologis memiliki sumbangan yang kuat dalam menentukan keputusan mahasiswa dalam memilih jurusan akutansi.

Oleh karena itu, penulis melakukan penelitian lebih lanjut tentang faktor psikologis yang mempengaruhi keputusan mahasiswa memilih jurusan di Fakultas Ilmu Sosial dan Ilmu Politik Universitas Islam Balitar.Penelitian ini diberi judul Pengaruh Motivasi, Persepsi, Pembelajaran dan Sikap Terhadap Keputusan Mahasiswa Memilih Jurusan (Studi Kasus di Fakultas Ilmu Sosial dan Ilmu Politik Universitas Islam Balitar). Empat variabel bebas penelitian kali ini terdiri darivariabel $\mathrm{X}_{1}$ yaitu Motivasi, $\mathrm{X}_{2}$ yaituPembelajaran, $\mathrm{X}_{3}$ yaitu Persepsi, $\mathrm{X}_{4}$ yaitu Sikap, serta ada satu variabel terikat Yyaitu Keputusan Mahasiswa Memilih Jurusan.Kerangka pemikiran pada penelitian ini dapat diketahui melalui Gambar 1. Berdasarkan Gambar 1 tersebutmaka dapat dirumuskan hipotesis penelitian:

$\mathrm{Ho}_{1}$ Diduga variabel motivasi (X1) tidak memiliki pengaruh terhadap variabel keputusan mahasiswa memilih jurusan (Y)secara parsial

$\mathrm{Ha}_{1}$ Diduga variabel motivasi (X1) memiliki pengaruh terhadap variabel keputusan mahasiswa memilih jurusan (Y)secara parsial

$\mathrm{Ho}_{2}$ Diduga variabel pembelajaran (X2) tidak memiliki pengaruh terhadap variabel keputusan mahasiswa memilih jurusan $(\mathrm{Y})$ secara parsial

$\mathrm{Ha}_{2}$ Diduga variabel pembelajaran (X2) memiliki pengaruh terhadap variabel keputusan mahasiswa memilih jurusan (Y)secara parsial

$\mathrm{Ho}_{3}$ Diduga variabel persepsi (X3) tidak memiliki pengaruh terhadap variabelkeputusan mahasiswa memilih jurusan (Y)secara parsial

$\mathrm{Ha}_{3}$ Diduga variabel persepsi (X3) memiliki pengaruh terhadap variabelkeputusan mahasiswa memilih jurusan (Y)secara parsial

$\mathrm{Ho}_{4}$ Diduga variabel sikap (X4) tidak memiliki pengaruh terhadap variabel keputusan mahasiswa memilih jurusan (Y)secara parsial

$\mathrm{Ha}_{4}$ Diduga variabel sikap (X4) memiliki pengaruh terhadap variabel keputusan mahasiswa memilih jurusan (Y)secara parsial

$\mathrm{Ho}_{5}$ Diduga empat variabel bebas (motivasi, pembelajaran, persepsi, sikap) tidak memiliki pengaruh kepada variabel terikat yaitu keputusan mahasiswa memilih jurusan (Y) secara simultan

$\mathrm{Ha}_{5}$ Diduga empat variabel bebas (motivasi, pembelajaran, persepsi, sikap) memiliki pengaruh kepada variabel terikat yaitu keputusan mahasiswa memilih jurusan (Y) secara simultan 


\section{REFORMASI}

ISSN 2088-7469 (Paper) ISSN 2407-6864 (Online)

Volume 10 Nomor 1 (2020)

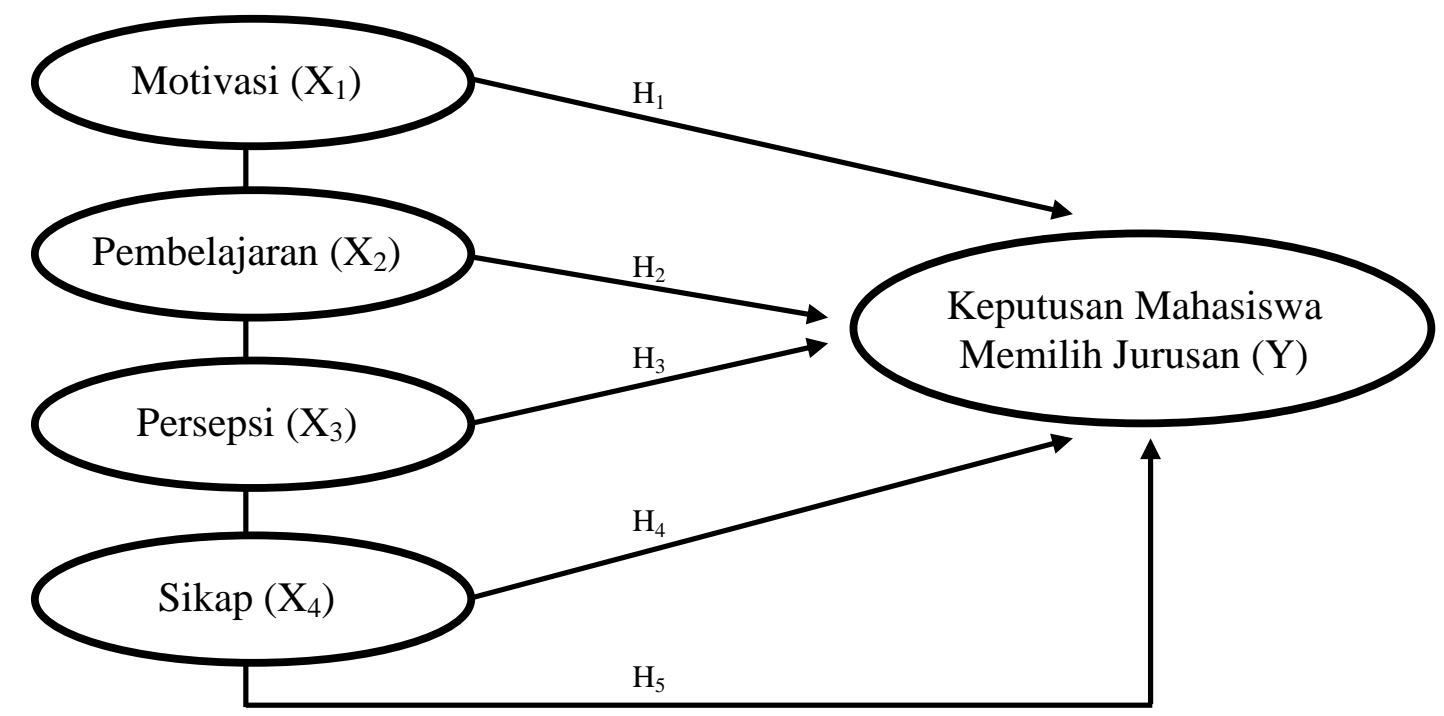

Gambar 1. Kerangka Pemikiran

\section{METODE PENELITIAN}

Metode penelitian yang dipakai pada penelitian ini adalah kuantitatif.Metode penelitian kuantitatif menurut Sugiyono (2009), adalah metode penelitian yang menekankan pada pengujianpengujian teori-teori melalui pengukuran variabel-variabel penelitian dengan angka dan melakukan analisis data dengan prosedur statistik (Indriantoro, 1999 dalam Sulistiyawan, 2008).Pengolahan hasil kuesioner diolah menggunakan bantuan alat atau aplikasi SPSS versi 18.Statistical Package for Social Science(SPSS) adalah salah satu programdalam penelitian statistik untuk membantu pengolahan, perhitungan dan analisis data secara statistik (Nugroho, 2005).

Dalam penelitian ini digunakan alat analisis kuantitatif yaitu analisa statistik dengan menggunakan program SPSS (Statistical Product and Service Sollution) 18.0 for Windows. SPSS 18.0 merupakan sebuah program komputer statistik yang berfungsi untuk membantu dalam memproses data-data statistik secara cepat dan tepat, serta menghasilkan berbagai output yang dikehendaki oleh para pengambil keputusan. Statistik dapat diartikan sebagai suatu kegiatan yang bertujuan untuk mengumpulkan data, meringkas atau menyajikan data kemudian menganalisis data dengan menggunakan metode tertentu, dan menginterpretasikan hasil dari analisis tersebut.Dalam perhitungan statistik, alat yang sering digunakan adalah pengolahan data SPSS. Program SPSS 18.0 ini sangat membantu dalam proses pengolahan data, sehingga hasil pengolahan data yang dicapai dapat dipertanggungjawabkan dan terpercaya.Program SPSS juga digunakan dalam melakukan uji instrumen sebelum penelitian dilaksanakan. Hasilnya instrument atau kuesioner yang akan digunakan pada penelitian ini dinyatakan sudah valid dan reliable.

Sebelum melakukan uji hipotesis, data yang ada perlu diuju menggunakan uji asumsi klasik.Menurut Hamdi dan Bahruddin (2014) bahwa asumsi klasik merupakan uji kehandalan suatu model maupun sebagai uji persyaratan dari suatu analisis.Uji asumsi klasik ini meliputi uji autokorelasi, uji multikolinieritas, uji normalitas dan uji heteroskedastisitas. Di sisi lain, menurut Sutopo dan Slamet (2017) uji autokorelasi hanya dilakukan pada data time series atau data dengan runtut waktu dan tidak perlu dilakukan pada data kuesioner yang datanya adalah cross section. Oleh karena itu, sebelum melakukan uji hipotesis, data hasil kuesioner dalam penelitian ini akan diuji terlebih dahulu menggunakan uji asumsi klasik dengan tiga uji saja yaitu uji normalitas, multikolinieritas dan uji heteroskedastisitas. 


\section{REFORMASI}

ISSN 2088-7469 (Paper) ISSN 2407-6864 (Online)

Volume 10 Nomor 1 (2020)

Uji asumsi klasik pertama yaitu uji normalitas menggunakan uji Kolmogorov-Smirnov dan menurut Santoso (2010), jika nilai Sig. > 0,05 maka data sudah berdistribusi normal. Uji asumsi klasik kedua yaitu hasil uji multikolinieritas. Menurut Zulfikar (2016), uji multikolinieritas dapat dilihat dari nilai VIF atau Variance Inflation Factor. Data dikatakan tidak terdapat hubungan antar variabel bebas ketika nilai VIF $>10$ dan sebaliknya jika VIF $<10$ maka tidak terjadi multikolinieritas. Uji asumsi klasik ketiga adalah uji heteroskedastisitas. Menurut Purnomo (2017), ketika nilai Sig. > 0,05 maka tidak terjadi masalah heteroskedastisitas. Sebaliknya, ketika nilai Sig. $<0,05$ maka dapat dikatakan terjadi heteroskedastisitas.

Setelah selesai dilakukan uji asumsi klasik maka selanjutnya yaitu uji hipotesis yang terbagi menjadi uji parsial dan uji simultan. Menurut Bungin (2017) pada uji parsial, jika nilai Sig. kurang dari 0,05 maka menolak Ho dan menerima Ha. Dengan kata lain, nilai sig kurang dari 0,05 artinya variabel bebas mempengaruhi variabel terikat, sebaliknya nilai sig.lebih dari 0,05 artinya variabel bebas tidak mempengaruhi variabel terikat. Menurut Mukhtar, Ali dan Mardalena (2016) pada uji simultan, jika nilai sig < 0,05 maka signifikan. Artinya menolak Ho dan menerima Ha.Sebaliknya nilai sig. $>0.05$ artinya menerima Ho dan menolak Ha.

\section{HASIL DAN PEMBAHASAN}

\section{Uji Asumsi Klasik}

Uji asumsi klasik pada penelitian ini menggunakan tiga uji saja yaitu uji normalitas, uji multikolinieritas dan uji heteroskedastisitas.Uji normalitas merupakan uji yang digunakan untuk mengetahui apakah sebaran data sudah berdistribusi normal.Uji multikolinieritas adalah uji yang digunakan untuk mengetahui ada tidaknya hubungan antara variabel bebas dalam sebuah penelitian.Uji ketiga yaitu uji heteroskedastisitas adalah uji yang digunakan untuk mengetahui apakah varians error yang dimiliki oleh data pengamatan berbeda dari satu pemngamatan ke pengamatan lainnya.

Hasil uji asumsi klasik disajikan pada Tabel 2. Uji pertama yaitu uji normalitas menggunakan uji Kolmogorov-Smirnov adalah 0,454 di mana sudah > 0,05 sehingga dapat disimpulkan bahwa distribusi data adalah normal. Hasil uji asumsi klasik kedua yang dapat dilihat pada Tabel 2 adalah hasil uji multikolinieritas. Berdasarkan hasil pengujian menggunakan SPSS pada Tabel 2, didapatkan hasil seluruh nilai VIF dari variabel $\mathrm{X} 1$ hingga $\mathrm{X} 4$ adalah $<10$, sehingga dapat disimpulkan tidak terdapat masalah multikolinieritas antar variabel bebas pada penelitian ini.

Hasil uji asumsi klasik ketiga pada penelitian ini adalah uji heteroskedastisitas yang ditunjukkan Tabel 1. Uji heteroskedastisitas pada penelitian ini menggunakan uji Spearman's rho dengan fokus melihat hasil nilai Sig. (2-tailed) pada setiap variabel bebas. Pada Tabel 2 dapat dilihat hasil uji heteroskedastisitas menggunakan uji Spearman's rho keseluruhannya adalah >0,05, sehingga dapat disimpulkan bahwa seluruh variabel pada penelitian ini terbebas dari masalah heteroskedastisitas.

Tabel 2. Hasil Uji Asumsi Klasik

\begin{tabular}{|c|c|c|c|c|c|c|}
\hline Variabel & $\begin{array}{l}\text { Asymp. Sig. } \\
\text { (2-tailed) }\end{array}$ & Hasil & VIF & Hasil & Sig. (2-tailed) & Hasil \\
\hline MOTIVASI (X1) & \multirow{5}{*}{0,454} & \multirow{5}{*}{ Normal } & 1,734 & \multirow{5}{*}{$\begin{array}{l}\text { Tidak } \\
\text { terjadi } \\
\text { masalah } \\
\text { multiko- } \\
\text { lineari-tas }\end{array}$} & 0,291 & \multirow{5}{*}{$\begin{array}{l}\text { Tidak } \\
\text { terjadi } \\
\text { masalah } \\
\text { heteros- } \\
\text { kedas- } \\
\text { tisitas }\end{array}$} \\
\hline PEMBELAJARAN (X2) & & & 1,288 & & 0,418 & \\
\hline PERSEPSI (X3) & & & 1,881 & & 0,773 & \\
\hline SIKAP $(X 4)$ & & & 1,255 & & 0,465 & \\
\hline $\begin{array}{l}\text { KEPUTUSAN } \\
\text { MAHASISWA MEMILIH } \\
\text { JURUSAN (Y) }\end{array}$ & & & - & & - & \\
\hline
\end{tabular}




\section{REFORMASI}

ISSN 2088-7469 (Paper) ISSN 2407-6864 (Online)

Volume 10 Nomor 1 (2020)

\section{Uji Hipotesis}

Uji hipotesis adalah langkah untuk menguji hipotesis atau kesimpulan sementara yang telah ditetapkan di awal penelitian. Pada penelitian ini, hasil uji hipotesis dibagi menjadi dua yaitu uji parsial dan uji simultan. Uji pertama yaitu uji parsial dilakukan untuk mengetahui pengaruh setiap variabel bebas terhadap variabel terikat. Hasil uji parsial dapat dilihat pada Tabel 3 di mana untuk melihat ada pengaruh tidaknya difokuskan pada kolom Sig. Berdasarkan hasil pada Tabel 3 diketahui nilai sig. variabel motivasi adalah 0,023 maka $\mathrm{Ho}_{1}$ ditolak dan $\mathrm{Ha}_{1}$ diterima.Artinya variabel motivasi memiliki pengaruh terhadap variabel keputusan memilih jurusan. Variabel pembelajaran juga memiliki nilai sig. kurang dari 0,05yaitu 0,023 , sehingga $\mathrm{Ho}_{2}$ ditolak dan $\mathrm{Ha}_{2}$ diterima. Artinya variabel pembelajaran memiliki pengaruh terhadap keputusan mahasiswa dalam memilih jurusan.Variabel persepsi dan variabel sikap memiliki nilai sig. yang sama yaitu 0,000 dan nilai tersebut kurang dari 0,05 . Oleh karena itu, $\mathrm{Ho}_{3}$ dan $\mathrm{Ho}_{4}$ sama-sama ditolak.Ha $\mathrm{Han}_{3} \mathrm{Ha}_{4}$ diterima yang artinya variabel persepsi memiliki pengaruh terhadap keputusan mahasiswa dalam memilih jurusan.Begitu juga dengan variabel sikap juga memiliki pengaruh terhadap keputusan mahasiswa dalam memilih jurusan.

\section{Tabel 3.Hasil Uji Parsial \\ Coefficients $^{\mathbf{a}}$}

\begin{tabular}{|c|c|c|c|c|c|c|}
\hline \multirow{2}{*}{\multicolumn{2}{|c|}{ Model }} & \multicolumn{2}{|c|}{$\begin{array}{l}\text { Unstandardized } \\
\text { Coefficients }\end{array}$} & \multirow{2}{*}{$\begin{array}{c}\text { Standardized } \\
\text { Coefficients }\end{array}$} & \multirow[b]{2}{*}{$\mathrm{t}$} & \multirow[b]{2}{*}{ Sig. } \\
\hline & & B & Std. Error & & & \\
\hline \multirow[t]{5}{*}{1} & (Constant) & .664 & .888 & & .748 & .455 \\
\hline & MOTIVASI & .125 & .055 & .143 & 2.286 & .023 \\
\hline & $\begin{array}{l}\text { PEMBELAJAR } \\
\text { AN }\end{array}$ & .127 & .062 & .110 & 2.048 & .042 \\
\hline & PERSEPSI & .175 & .041 & .281 & 4.314 & .000 \\
\hline & SIKAP & .359 & .057 & .333 & 6.273 & .000 \\
\hline
\end{tabular}

a. Dependent Variable: KEPUTUSAN MEMILIH JURUSAN

Uji hipotesis selanjutnya yang dilakukan setelah uji parsial adalah uji simultan.Uji Simultan adalah uji yang dilakukan pada data kuesinor untuk mengetahui apakah variabel bebas mempengaruhi variabel terikat secara bersama-sama. Uji simultan pada penelitian ini berupaya mengetahui apakah keempat variabel bebas mempengaruhi variabel terikat secara bersama-sama atau tidak. Hasil uji simultan pada penelitian ini dapat dilihat pada Tabel 4 dengan fokus pada kolom nilai Sig. Pada penelitian kali ini didapatkan hasil uji simultan seperti yang terlihat pada Tabel 4 yaitu nilai sig. 0,000. Nilai tersebut kurang dari 0,05 sehingga $\mathrm{Ho}_{5}$ ditolak dan $\mathrm{Ha}_{5}$ diterima. Artinya secara bersama-sama variabel sikap, variabel pembelajaran, variabel motivasi dan variabel persepsi mempengaruhi keputusan mahasiswa dalam memilih jurusan. 
Tabel 4. Hasil Uji Simultan

ANOVA ${ }^{b}$

\begin{tabular}{|ll|r|r|r|r|r|}
\hline \multicolumn{1}{|l|}{ Model } & \multicolumn{1}{|c|}{$\begin{array}{c}\text { Sum of } \\
\text { Squares }\end{array}$} & df & Mean Square & F & Sig. \\
\hline 1 & Regression & 380.526 & 4 & 95.131 & 49.570 & $.000^{\mathrm{a}}$ \\
& Residual & 472.104 & 246 & 1.919 & & \\
& Total & 852.629 & 250 & & & \\
\hline
\end{tabular}

a. Predictors: (Constant), SIKAP, PEMBELAJARAN, MOTIVASI, PERSEPSI

b. Dependent Variable: KEPUTUSAN MEMILIH JURUSAN

\section{Pembahasan}

Pada penelitian ini didapatkan hasil bahwa baik secara parsial dan secara simultan, keempat variabel bebas yaitu sikap, pembelajaran, motivasi dan persepsi mempengaruhi mahasiswa Fakultas Ilmu Sosial dan Ilmu Politik Universitas Islam Balitar dalam memilih jurusan. Hal ini sejalan dengan model perilaku konsumen yang diusung oleh Kotler dan juga pendapat dari Firmansyah (2018) bahwa dalam membuat keputusan ada banyak faktor yang mempengaruhi. Salah satu faktor yang mempengaruhi seseorang dalam membuat keputusan adalah dari karakteristik orang itu sendiri atau disebut dengan faktor psikologis. Faktor psikologis ini terdiri dari sikap, pembelajaran, kepribadian dan kepribadian. Di sisi lain, menurut Morissan (2015), motivasi juga masuk ke dalam salah satu faktor psikologis seseorang dalam membuat keputusan. Oleh karena itu, ke depannya Universitas Islam Balitar, khususnya Fakultas Ilmu Sosial dan Ilmu Politik sangat perlu memperhatikan faktor psikologis tersebut agar ke depannya semakin banyak lagi mahasiswa yang akan memilih jurusan di Fakultas Ilmu Sosial dan Ilmu Politik, Universitas Islam Balitar.

\section{KESIMPULAN}

Kesimpulan yang dapat ditarik pada penelitian kali ini adalah variabel sikap, variabel pembelajaran, variabel motivasi dan variabel persepsi yang merupakan variabel bebas, keempatnya memiliki pengaruh terhadap variabel terikat yaitu keputusan mahasiswa dalam memilih jurusan baik secara parsial maupun secara simultan. Mahasiswa Fakultas Ilmu Sosial dan Ilmu Politik dalam menentukan jurusan terbukti mempertimbangkan faktor psikologis yang meliputi sikap, pembelajaran, motivasi dan persepsi mereka. Baik secara sendiri-sendiri maupun secara bersama-sama, keempat faktor tersebut mempengaruhi mahasiswa dalam menentukan jurusan di Fakultas Ilmu Sosial dan Ilmu Politik, Universitas Islam Balitar. Fakultas Ilmu Sosial dan Ilmu Politik, Universitas Islam Balitar diharapkan ke depannya lebih memperhatikan lagi beberapa faktor penting seperti faktor psikologis yang memiliki pengaruh terhadap keputusan mahasiswa memilih jurusan di Fakultas Ilmu Sosial dan Ilmu Politik, Universitas Islam Balitar.

\section{DAFTAR PUSTAKA}

Alma, Buchari dan Hurriyati, Ratih.2008. Manajemen Corporate dan Strategi Pemasaran Jasa Pendidikan Fokus Pada dan Layanan Prima. Bandung. Penerbit Alfabeta.

Bungin, Burhan. 2017. Metodologi Penelitian Kuantitatif. Jakarta. Kencana.

Firmansyah, M. Anang. 2018. Perilaku Konsumen: Sikap dan Pemasaran. Yogyakarta.Deepublish.

Hamdi, Asep Saepul dan Bahruddin, E. 2014.Metode Penelitian Kuantitatif Aplikasi dalam Pendidikan.Yogyakarta.Deepublish. 


\section{REFORMASI}

ISSN 2088-7469 (Paper) ISSN 2407-6864 (Online)

Volume 10 Nomor 1 (2020)

Harahap, Fadli. 2015. Analisis Faktor-Faktor Yang Mempengaruhi Keputusan Mahasiswa Dalam Memilih Jurusan Akutansi Sebagai Tempat Kuliah di Universitas di Kota Pekanbaru. JOM.FEKON.2 (2).

Morissan. 2015. Periklanan: Komunikasi Pemasaram Terpadu. Jakarta. Prenadamedia Group.

Mukhtar, Ali, Hapzi dan Mardalena. 2016. Efektivitas Pimpinan: Kepemimpinan Transformatif dan Komitmen Organisasi. Yogyakarta.Deepublish.

Purnomo, Rochmat Aldy. 2017. Analisis Statistik Ekonomi dan Bisnis dengan SPSS Cetakan Ketiga.Ponorogo.UNMUH Ponorogo Press.

Santoso, Singgih. 2010. Statistik Multivariat. Jakarta. PT Elex Media Komputindo.

Sulistiyawan, Fauzan. 2008. Pengaruh Retailing Mix Terhadap Keputusan Pembelian Pada Alfamart di Jl. Gajayana Malang. Skripsi. Sarjana Ekonomi. Universitas Islam Negeri Malang. Malang.

Sutopo, Yeri dan Slamet, Achmad. 2017. Statistika Inferensial. Yogyakarta. Penerbit ANDI.

Zulfikar.2016. Pengantar Pasar Modal dengan Pendekatan Statistika.Yogyakarta.Deepublish. 